\title{
Teaching with Digital 3D Models of Minerals and Rocks
}

Graham D.M. Andrews*, Gabrielle D. Labishak, Sarah R. Brown, Shelby L. Isom, Holly D. Pettus, and Trevor Byers, Dept. of Geology

\& Geography, West Virginia University, Morgantown, West Virginia 26506, USA

The disruption to geoscience curricula due to the COVID-19 pandemic highlights the difficulty of making mineral and rock samples accessible to students online rather than through traditional lab classes. In spring 2020 , our community had to adapt rapidly to remote instruction; this transition amplified existing disparities in access to geoscience education but can be a catalyst to increase accessibility and flexibility in instruction permanently. Fortunately, a rich collection of 3D mineral and rock samples is being generated by a community of digital modelers (e.g., Perkins et al., 2019).

\section{THE NEED}

Exposing students to mineral and rock samples is an essential component of most earth-science classes. However, we lack a widely accepted and accessible method to teach basic rock and mineral description, identification, and classification other than with physical hand samples. This impedes online teaching of geoscience, and it seems obvious that this restricts the potential for growth in online classes. It discriminates against differently abled students and those unable to attend typical in-person classes (e.g., Carabajal et al., 2017). Furthermore, the emphasis on physical samples favors programs with large and diverse sample collections: often older, better-funded, and more prestigious schools.

Digital samples have the potential to address many of these problems albeit with some drawbacks. "Virtual Rocks" (De Paor, 2016) have been generated from real samples for as long as 3D scanning technology has been available but have had limited impact and application. The development of low-cost and rapid structure-from-motion photogrammetry techniques means that a model can now be made in less than an hour using a cellphone camera and free or lowcost software on a consumer-grade computer. Sharing and viewing scientific 3D models is now routine and 3D printers and virtual-reality headsets are now commonplace in schools and many homes. So why has this technology not taken off in geology programs?

\section{IMPEDIMENTS TO ADOPTION}

Major advances in making digital geoscience data available have not been distributed equally between or within specific core disciplines. For example, the teaching of petrology has digital support for intermediate and advanced classes in microscopy, petrography, and virtual field trips (e.g., Cho and Clary, 2020). However, most efforts are directed to upper-level classes for geology majors and are less useful for introductory classes where the most students will engage with rocks and minerals, often for the first and only time.

Personal experience and anecdotal evidence gathered from online discussions support the conclusion that many faculty feel that students must be able to handle mineral and rock samples to develop a complete understanding. There is no doubt that elements of mineral identification are heavily dependent on physical interaction with specimens: hardness tests, steak-plate tests, heft, and feeling the soapiness of talc, for example. But if these cannot be replicated in an online environment, is that justification to not use digital models? We say "no"-many important observations of minerals, and most observations of rock samples, can be and often must be made by eye. Are field photographs of outcrops undermined by not being able to "lick the rock"? Here, we describe our first-hand experiences using digital models during the migration to online instruction in March 2020.

\section{DIVING IN}

We set out to develop an online collection of digital models of volcanic rocks and textures in spring 2019 to (1) take advantage of our large and diverse sample collection, including many unique samples; (2) make models available for remote instruction; and (3) share models with geoscience educators freely. Upon recognizing that model production was straightforward, we expanded our target samples to include a small suite of minerals and rocks for "Introduction to Minerals and Rocks," a required class for geology majors. As soon as COVID-19 disruption became critical, we produced models for a representative suite of rock samples, mainly igneous and metamorphic.

\section{MODEL CONSTRUCTION AND DISSEMINATION}

Our photography set-up consists of a lightbox, turntable, LED lights, and an $18 \mathrm{MP}$ digital camera on a tripod (Fig. 1A), costing less than US\$100 without the camera. We use Agisoft Metashape Pro photogrammetry software (Fig. 1B; annual academic license US $\$ 559^{* *}$ ) on graphics-accelerated PCs noting processing time scales with RAM, and processor and GPU speeds. The model is uploaded to Sketchfab.com (http:// sketchfab.com/WVUpetrology; Fig. 1C) where we store and share it. A Sketchfab Pro academic license is US\$100. All our models have digital object identifiers and are free to download. Our workflow

GSA Today, v. 30, https://doi.org/10.1130/GSATG464GW.1. Copyright 2020, The Geological Society of America. CC-BY-NC.

*Email: gda0005@mix.wvu.edu.

${ }^{* *}$ Correction: This original version of this article identified the software as Agisoft Metashape Basic photogrammetry software with an annual academic license price of US\$59, but at press time the authors became aware that Pro is now required. The article was modified to reflect this. 


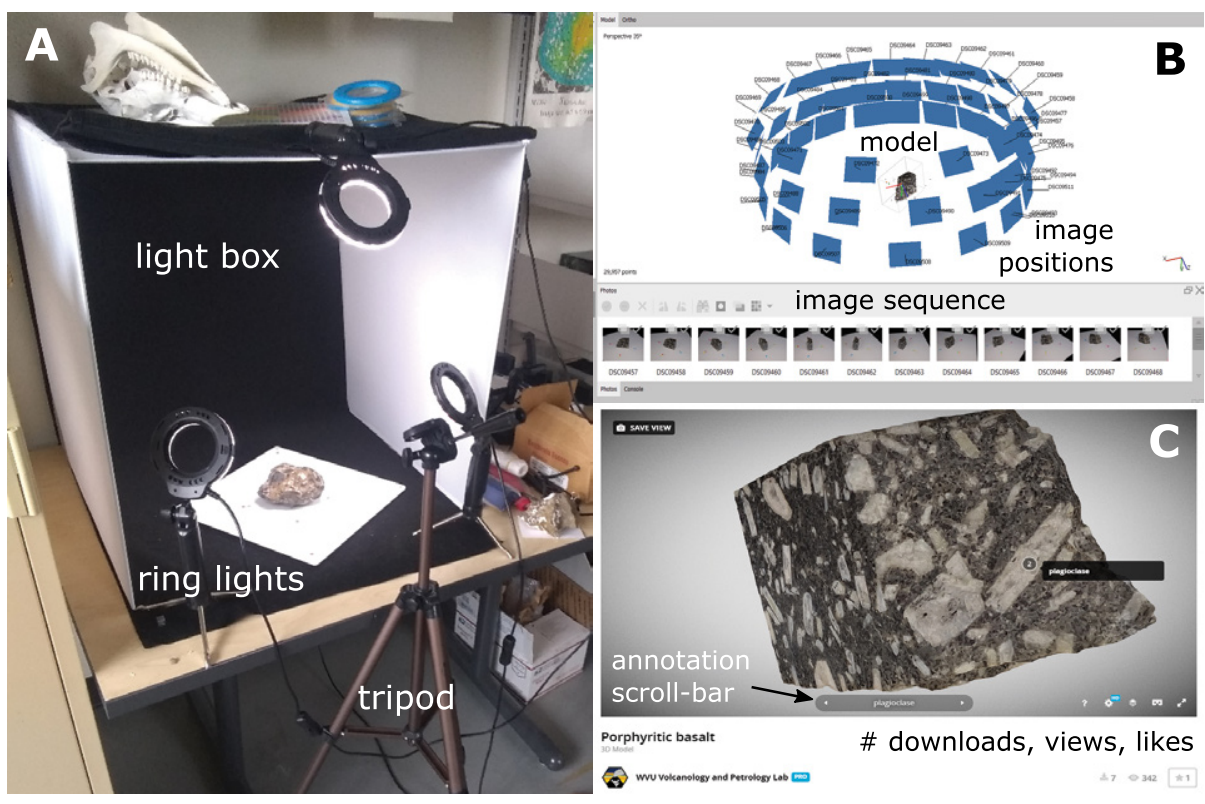

Figure 1. (A) Sample photography setup. (B) Model construction in Agisoft Metashape. (C) Finished model on Sketchfab.com.

(Supplemental Material ${ }^{1}$ ) is explained in a series of YouTube videos (currently in production; see https://www.youtube.com/ watch? $v=s 6$ D6xFee7fU). Students can be trained quickly and be making models the same day. The software struggles to replicate reflective samples, those with homogeneous color, and those with complex morphologies.

\section{CURATED SKETCHFAB COLLECTIONS}

Our most novel action is to divide our samples into thematic collections on Sketchfab .com (http://sketchfab.com/WVUpetrology/ collections) and to systematically add over 80 other users' models. As of June 2020, we have collections for minerals $(n=201)$, crystallography (53), igneous (320), metamorphic (276), sedimentary (255) and volcanic (251) rocks, meteorites (26), and fault-related rocks (28). New models are added daily. Samples range from mundane minerals and rocks essential for introductory classes through to museumquality specimens. Samples divide into those that are labeled and those that come without information to facilitate online quizzes.

\section{USE DURING COVID-19}

Digital models cannot substitute for physical hand samples without changing the structure of lab classes. Limited assessment data indicate that students enjoy the virtual interaction and are confident with the technology (Alelis et al., 2015), and that they appreciate the flexibility it allows (Cho and Clary, 2020). However, students miss the hands-on examination and testing of specimens, and interactions with other students.

Rather than trying to substitute digital models in extant labs, we redesigned our labs around the digital models and virtual field trips. Enough models were available to introduce and apply modal mineral analyses to plutonic rocks and to allow students to reliably identify phenocrysts and porphyroblasts, for example. Students were able to distinguish between different rock types and to interpret textural information from the $3 \mathrm{D}$ models (e.g., bedding, etc.). Where important mineral information is not obvious (e.g., calcite reacting to $\mathrm{HCl}$ ), we provide the necessary information in the questions.

\section{FINAL THOUGHTS}

Digital models of minerals and rocks are easy to produce and deploy in online classes, and although imperfect, they have advantages over hands-on samples when labs are redesigned accordingly. A large and growing collection of samples is being generated on Sketchfab.com, meaning that there has never been an easier time to include 3D models in your classes.

\section{REFERENCES CITED}

Alelis, G., Bobrowicz, A., and Ang See Chiang, 2015, Comparison of engagement and emotional responses of older and younger adults interacting with 3D cultural heritage artefacts on personal devices: Behaviour \& Information Technology, v. 34, no. 11, p. 1064-1078, https://doi.org/10.1080/ 0144929X.2015.1056548.

Carabajal, I.G., Marshall, A.M., and Atchison, C.L., 2017, A synthesis of instructional strategies in geoscience education literature that address barriers to inclusion for students with disabilities: Journal of Geoscience Education, v. 65 , p. 531-541, https:// doi.org/10.5408/16-211.1.

Cho, Y., and Clary, R.M., 2020, Challenges and opportunities for virtual learning in college geology, in Mintzes, J.J., and Walters, E.M., eds., Active Learning in College Science: Cham, Switzerland, Springer Nature, https://doi.org/10.1007/978-3 -030-33600-4_44.

De Paor, D.G., 2016, Virtual rocks: GSA Today, v. 26 , no. 8 , p. 4-11, https://doi.org/10.1130/ GSATG257A.1.

Perkins, D., Stene, N., Schultz, A., Bentley, C., and Hollister, R., 2019, Rocks and minerals-A library of 3-dimensional images for classroom use: Geological Society of America Abstracts with Programs, v. 51, no. 5, https://doi.org/ 10.1130/abs/2019AM-335150.

Manuscript ReCeived 28 Apr. 2020

Revised manusCript ReCEIVEd 9 June 2020

ManusCript accepted 11 June 2020

\footnotetext{
${ }^{1}$ Supplemental Material: methodology. Please visit https://doi.org/10.1130/GSAT.S.12493373 to access the supplemental material, and contact editing@geosociety.org with any questions.
} 